\title{
The microfoundations of design sprint: how Johnson \& Johnson cultivates innovation in a highly regulated market
}

\author{
Stefano Magistretti, Luis Allo, Roberto Verganti, Claudio Dell'Era and Felix Reutter
}

\author{
Stefano Magistretti is based at \\ the School of Management, \\ Politecnico di Milano, Milan, \\ Italy. Luis Allo is based at \\ Consumer Health Division of \\ Cilag GmbH International, \\ Johnson and Johnson, Zug, \\ Switzerland. Roberto Verganti \\ is based at the Stockholm \\ School of Economics, \\ Politecnico di Milano, Milano, \\ Italy. Claudio Dell'Era is based \\ at the School of Management, \\ Politecnico di Milano, Milan, \\ Italy. Felix Reutter is based at \\ the Consumer Health Division \\ of Cilag GmbH International, \\ Johnson and Johnson, Zug, \\ Switzerland.
}

Received 9 September 2020 Revised 15 December 2020 4 February 2021 Accepted 12 February 2021

(C) Stefano Magistretti, Luis Allo, Roberto Verganti, Claudio Dell'Era,

Felix Reutter. Published by Emerald Publishing Limited. This article is published under the Creative Commons Attribution (CC BY 4.0) licence. Anyone may reproduce, distribute, translate and create derivative works of this article (for both commercial and non-commercial purposes), subject to full attribution to the original publication and authors. The full terms of this licence may be seen at http://creativecommons.org/ licences/by/4.0/legalcode

\begin{abstract}
Purpose - Mastering innovation in highly regulated markets might require companies to overcome significant barriers. Rules, laws and limitations on social, economic and institutional dimensions can hinder the ability of a company to transfer knowledge within and across organizational boundaries. However, as recent research in innovation management increasingly advocates user involvement and early understanding of user needs as best practices, the inability to freely interact with customers due to highly regulated market restrictions can hinder the company's capability to innovate. Hence, this paper aims to shed light on how an emerging managerial approach, such as Design Sprint, can support companies operating in highly regulated markets to overcome user involvement limitations and boost human-centered innovation.

Design/methodology/approach - This paper sheds light on how to boost innovation in a highly regulated market by leveraging an in-depth case study. The study investigates the use of the Design Sprint approach adopted by the pharmaceutical multinational Johnson \& Johnson to revise the way its $R \& D$ department orchestrates the new product development process, overcoming the user involvement challenges of highly regulated markets.

Findings - In analyzing six different projects undertaken in the past two years, the findings illustrate three microfoundational dimensions of the Design Sprint approach in highly regulated markets, the so-called 3T model: team, time and tools. Indeed, deploying the Design Sprint in a highly regulated market has proven that being able to experiment in the early stages, building rough prototypes in real-time and openly collaborating with partners is crucial to boost innovation and anticipate constraints.

Originality/value - The paper sheds light on the Design Sprint approach by initially grounding an emerging managerial approach on organizational and management theory, leveraging the lens of microfoundations. In doing so, this study suggests how Design Sprint is based on the pillars of experimentation, knowledge transfer and co-creation usually neglected in highly regulated markets where user involvement is challenging. Finally, this study discloses the importance of using a designbased methodology in fostering innovation in highly regulated markets.
\end{abstract}

Keywords Design sprint, Knowledge transfer, Open innovation, Experimentation, Design thinking, Microfoundations, Design sprint

Paper type Research paper

\section{Introduction}

Making innovation happen is always difficult (Barczak et al., 2009). Cultural, technical, political, market and social reasons are just some of the many that can constrain the innovativeness of companies (Foxon and Pearson, 2008; Madrid-Guijarro et al., 2009). In literature, there is a growing debate about the role that regulations might have in innovations (Amable et al., 2016; Blind et al., 2017). Regulations can be linked to different sources, economic, social and institutional, depending on whether they are related to price, to consumer safety or to laws (Blind, 2016; Marino et al., 2019). These are just examples of the types of regulation that influence our markets and companies operating in them. Thus, in a 
world where competitive advantage is no longer durable, and continuous technological evolution requires firms to manage the business with ambidextrous tension (Gibson and Birkinshaw, 2004), more knowledge is needed on how companies can explore new technological opportunities under these different types of regulations.

A regulated market is defined as a type of business that is controlled by government rules, laws and requirements (Schiavone and Simoni, 2019). The results of inducements and limitations, due to regulations, can have unpredictable results over innovation. Companies can feel the need to comply with rules and limit their discovery opportunities or use the regulations as an opportunity creation source (Blind, 2016). Despite this debate, what is evident is that different sectors react differently. Indeed, there are sectors that need to comply with more strict regulatory frameworks than others. The regulations and dynamics in the pharmaceutical industry are more complex than in other fields, having a higher impact on product development (McKelvey et al., 2003). To ensure product and customer safety, pharmaceutical companies undergo validation processes for new products and components that are way more regulated if compared to approval procedures in other industries, such as for consumer goods. Indeed, the approval process for new drugs takes around five years to complete, and the procedures to devise new drugs involves the following steps. During an initial phase, the companies acknowledge a new market request or the need for a new production process; this might come from the voice of a customer or from the R\&D lab; nevertheless, this phase stays usually within the boundaries of the company. Second, there is a request for budget approval that usually already needs a set of detailed documentation to be circulated internally. Third, team creation. Fourth, the development of the actual innovation. Fifth, the start of the approval process. Sixth, after the approval comes a first trial on users, then a second approval and then the scale will come. It is evident that this process has several limitations. Despite this long and tortuous journey, pharmaceutical companies struggle to find new approaches towards innovation within this highly regulated environment. Companies in the pharmaceutical industry are enduring a highly regulatory framework; thus, they often face innovation management issues, especially concerning risks, with culturally and technologically disruptive innovations. The reasons include accountability towards the regulator, obtaining market trust, attaining market acceptance of new formulas and solutions, especially when the focus shifts from breakthrough therapies for severe illnesses, where budgets and experimentation costs are higher, to mass-market products sold Over the Counter (OTC). OTC products require different procedures to be invented and innovated. Always more frequently in the practitioners' world we can recognize how understanding user needs in this area, the OTC, would lead to greater market success. Despite this and due to the highly regulated market, users are not allowed to be asked to perform early user tests or trial as in other fields, i.e. the digital one. Companies cannot ask people to swallow drugs that are not approved or clinically tested. This detachment from the end-user is counterintuitive with respect to the experimentation movement (Malsch and Guieu, 2019; Thomke, 2020) and the innovation guided by user needs (Carlgren et al., 2016; Kyakulumbye et al., 2019). Thus, it is actually difficult to imagine how companies engage users and foster innovation within such a context; this study considers precisely this perspective over the highly regulated market.

Design thinking is considered one of the main approaches for solving user needs by empathizing and reframing problems (Carlgren et al., 2016); however, it seems not to be applicable in an environment where the user cannot be involved. All the agile and sprint developments that leverage early prototyping and testing (Magistretti et al., 2020a) are equally limited in adoption due to the difficulties in understanding when a solution or a so called "minimum viable product" can be launched and tested in the market, if not yet approved (Trabucchi et al., 2020). Even extreme approaches such as Design Sprint by Google (Knapp et al., 2016), where the idea is to solve big problems in just five days, seems to be not applicable due to the social regulation on product and customer safety. Despite this, studies are increasingly showing the benefit of such approaches in many 
contexts (Liedtka, 2018; Brand et al., 2019). Actually, adopting Design Thinking, Design Sprint or experimentation approaches is clearly difficult in highly regulated markets (Cooper and Sommer, 2016; Dell'Era et al., 2020), where the limitation regards the involvement of end users, crucial element for these approaches. Thus, more research is needed on how companies can leverage Design Sprint to boost innovation in a highly regulated market when end users are difficult to be involved.

To address this question, we searched for a company in the pharmaceutical sector that could help us understand how companies in highly regulated markets deal with innovation. This led us to one of the major players in the pharma industry, Johnson and Johnson (J\&J), who helped us shed light on the way it deployed Design Sprint as a mindset to foster innovation. Specifically, we analyzed six recent projects and interviewed managers from the R\&D department operating at both European and worldwide level, which led to some particularly interesting findings on sprint execution in a regulated market where end users are not involved freely. First, the process is reversed and considered from the inside instead than from the outside. Second, counterintuitively, in highly regulated markets, the involvement of external partners in the early stages of the innovation process is crucial. Third, the experimentation logic is essential to boost innovation despite the complexity in engaging end users in the presence of a regulator.

\section{Theoretical background}

The focus of the research is twofold. First, it deals with innovation in a highly regulated market. Second, it tries to encompass the lack of understanding of how Design Sprint deals with uncertainty within regulations. Thus, two different sections of literature are proposed.

\section{Innovation in highly regulated markets}

Innovation is defined as the ability to create and capture value (Schubert and Tavassoli, 2020). Uncertainty over the outcome always plays a role in how creation and capture are managed (Quan et al., 2020). Uncertainty can be driven by many factors, such as market turbulence, technological issues and societal issues (Luukkonen, 1998; Sawhney and Prandelli, 2000; Von Zedtwitz, and Gassmann, 2002; Wang et al., 2015; Bicen and Johnson, 2015). Nevertheless, not much is known about the influence of regulations on innovations in different markets (Amable et al., 2016; Blind et al., 2017). A regulated market is defined as a type of business that is controlled by government rules, laws and requirements (Schiavone and Simoni, 2019). Moreover, regulations can pertain economic, social and institutional dimensions (Blind, 2016). Researchers show how societal and institutional regulations are usually more related to the interaction with entities within and outside companies while economic regulations refer to price policies and governmental laws (Marino et al., 2019). Despite the regulation dimension, an emerging issue is the growing perception that existing rules might hinder companies' innovation propensity due to the fact that they consider them as limitation to their innovation capability. In a world where open innovation (Chesbrough, 2006), user involvement (Micheli et al., 2019) and corporate entrepreneurship (Kreiser et al., 2019) are growing, imagining industry that albeit strict rules are capable of experimenting and fostering sprint innovation is difficult.

Indeed, the results of inducements and limitations, due to regulations, are shown to have unpredictable results over innovation (Amable et al., 2016). Companies can feel the need to comply with rules and limit the innovation activity to process innovation, thus ultimately efficiency, or use the regulations as an opportunity source by seeking new ways to generate value (Blind, 2016). Literature shows that there are sectors that have more strict regulatory frameworks than others. By way of example, the regulations and dynamics in the pharmaceutical industry are more complex than in other fields, having a stronger impact on product development (McKelvey et al., 2003). Under highly regulated frameworks, 
pharmaceutical companies are not allowed to use early user testing or perform trials of not approved products. Given the undebated value of user involvement in the early stages of innovation, this is a huge limitation for fostering innovation (Micheli et al., 2019). Indeed, companies cannot ask people to swallow not approved or not clinically tested drugs. This detachment from the end-user is counterintuitive with reference to the movement of experimentation (Malsch and Guieu, 2019; Thomke, 2020) and innovation guided by user needs (Kyakulumbye et al., 2019). Design thinking is considered one of the most promising approaches for solving user needs by empathizing and reframing problems (Carlgren et al., 2016), and it seems not to be applicable in such environments, where the user cannot be involved due to strict regulations. Similarly, agile and sprint development that leverage early prototyping and testing to experimentation (Thomke, 2020) are equally limited in the adoption due to the difficulties in understanding when the so called minimum viable product, if not approved, can be launched and tested in the market. Finally, Open Innovation, with its mantra of crossing the company boundaries to innovate, is equally hindered by the strict rules and the risk of spillover in such a complex environment (Chesbrough, 2006). Thus, new investigations on how emerging approaches intentionally invented to overcome barriers, manage uncertainty and solve big problems in just five days as Design Sprint (Knapp et al., 2016) might be of help to unshadow the value of its principles in a highly regulated market.

\section{Design sprint}

As mentioned above design and especially design management is recognized as a powerful approach to reduce uncertainty (Knapp et al., 2016) and create new visions (Verganti, 2009; Artusi et al., 2020). Studies have shown that adopting a design mindset can help embracing ambiguity and fostering innovation even when the problems are wicked and ill-defined (Buchanan, 1992; Magistretti et al., 2020a). In discovering new technologies, knowledge and uncertainty are always considerable, and the search for the right application might require different and complex iteration and experimentation processes (Savino et al., 2017; Magistretti et al., 2020b). Thus, in 2016, Google Ventures crafted a new approach deeply rooted on experimentation, design and agile mindsets called Design Sprint (Knapp et al., 2016; Pellizzoni et al., 2020). Design Sprint is a method adopted within and outside Google where the core is sketching, testing and prototyping an idea in just five days (Wilson and Doz, 2011). Despite the wide adoption of the methodology in the practitioners' world, academic literature is still lacking a theoretical understanding of Design Sprint. Current research unveils how it is rooted on different configurations, leveraging various prototype techniques and how it might support the envisioning of new opportunities by focusing on execution (Magistretti et al., 2020b). Despite this initial evidence, there are no discussions about Design Sprint microfoundations, defined as individuals, processes and structure (Barney and Felin, 2013; Wu and Lee, 2017) of this approach able to unveil the routines and capabilities (Felin et al., 2012) that determine this way of managing innovation.

The literature shows how Design Sprint brings together business, lean startup (Cavallo et al., 2020) and design thinking (Dorst, 2011) perspectives. The strong focus of Design Sprint on execution and prototyping is the essence of the minimum viable product (Ries, 2011), and testing and prototyping is the basis of every design thinking process (Brown, 2008). The combination of design approaches and entrepreneurial ones is considered a promising methodology toward fostering innovation in situations of uncertainty and market turbulence (Mansoori and Lackeus, 2019). Despite this, whether this tension toward execution and experimentation can be adopted everywhere or is limited to some industries, i.e. entrepreneurial venture or digital settings, is still unclear. Moreover, in adopting execution driven approaches, Design Sprint shifts the focus from strategy creation to strategy implementation (Cooper, 2016). Therefore, the focus is no longer on spending time 
on the creation and formulation of the best strategy, but on implementing the idea as soon as possible to prevent bias in assessing its validity with customers (BenMahmoud-Jouini and Midler, 2020).

The extant literature does not debate about how to embrace this design, experimentation and execution mindset, ultimately Design Sprint, when operating in a highly regulated market, where the involvement of customers to assess the validity of the initial assumptions cannot freely occur. In Design Sprint, iterations and continuous learning are crucial (Jin-Hai et al., 2003), both for the company and for the innovation itself. Indeed, when companies operate in highly regulated markets, the presence of a regulator might strongly affect the innovation process, especially in terms of iteration, experimentation and the early involvement of partners in open collaboration, whether they are suppliers or end users. This paper therefore aims to investigate how companies operating in highly regulated markets can adopt design methodologies that require user-centered approaches.

\section{Methodology}

Given the focus of this study, we adopt an exploratory case study methodology (Yin, 2011). Understanding the characteristics of companies operating in highly regulated markets and how adopting the design method might help them innovate faster requires a methodology that allows the researcher to gather data and evidence in a deeper and more unbiased way than in a quantitative study. In exploratory case studies, the sampling is crucial (Siggelkow, 2007). Thus, we searched for an extreme case that encompassed two constraints of our setting, first, that it operated in a highly regulated market; second, that would be inspiring in terms of the adoption of Design Sprint. The decision to opt for an extreme case is due to the novelty of the topic and the need to unfold evidence in such a complex setting. Extreme cases are defined as those where the dependent or independent variables analyzed differ greatly from other cases in the industry (Seawright and Gerring, 2008), leading to a better understanding of the phenomenon under study, even if lacking generalizability (Donmoyer, 2000). In our framing, the industry selected is the pharmaceutical due to its highly regulated characteristics that go from governmental rules, laws and requirements to the definition of end user involvement and testing new technologies. The focus of this study is in particular on the involvement of end users. Technology is usually defined in this industry as a new drug component developed in their R\&D labs or as new solutions to deliver and improve the efficacy of OTC products. To better understand how Design Sprint can be deployed in such environment, we selected Johnson \& Johnson (J\&J), a multinational corporation operating in this industry that has been adopting Design Sprint for some years to foster innovation.

By adopting a purposeful sampling, we selected J\&J for four main reasons. First, it operates in a highly regulated industry. Second, J\&J defines itself as a family of companies, a holding that sparks innovation and experiments different approaches for the benefit of many sub brands. Third, it was capable of overturning a traditional perception over time in the development of new solutions, moving from years to weeks for validating intuitions and not drugs. Moreover, we selected J\&J since for their need to speed up the innovation process they relied on design management practices and especially on Design Sprint to reframe the invention phase. These are evident signs of an extreme case of a company operating in a highly regulated market and not suffering from its rules but leveraging them for innovation and opportunity creation.

\section{Data collection and analysis}

After the first round of exploratory interviews with managers in the R\&D department, we selected in particular six different innovation projects that the company had carried out in the past couple of years to delve deeper in understanding the role of Design Sprint in reshaping the innovation process, when end users could not be involved freely due to strict 
regulations. These projects range from packaging $(\mathrm{S} 1, \mathrm{~S} 2)$ to new market launches (S3, S4), from addressing actual issues (S5) to exploring new problem spaces (S6). Albeit these differences in the output, all projects have been run through Design Sprint and were subject of strict regulations. This guaranteed a good homogeneity among the projects and supporting the emergence of evidence over the methodology itself. Table 1 reports a synoptic view over the six projects proposing, for confidentiality reasons, a code as reported above.

The second round of interviews saw the involvement of the R\&D Manager of Consumer and Self Care and the Director of the R\&D department. We followed a semi-structured process for interviewing managers about the different projects. The Appendix shows the protocol followed, which is organized in four main dimensions. We started by asking about the participation in the project, how it was managed, then we moved to the detailed analysis of the process, phases, tools and activities performed; third, we asked about the purposes of the project, why it was set up and its goals, we concluded with questions on the prototyping activity. We collected the data both from primary and secondary sources as reported in Table 2, and we leveraged them in different ways. By following the suggestion by Giudici et al. (2018), we specified the usage of them in the analysis.

After gathering the data, we proceeded to the categorization and classification phase, considered the best approach to qualitative data analysis. Indeed, Huberman and Miles (2002) report that the researcher's ability to categorize the data according to the nature of the evidence can inspire the classification of insights at different moments in time. In particular, we followed a four-step approach. First, researchers reviewed all the data gathered individually to make a personal sense of them. Thus, each researcher analyzed all the data to search for commonalities and differences in the way J\&J deployed the Design Sprints. Second, all the authors interacted together to extrapolate from the data the most inspiring information. Third, by triangulating the data with the microfoundational theoretical

\section{Table 1 Description of the analyzed projects}

\section{Sprint project code}

S1

S2

S3

S4

S5

S6

\section{Aim of the project}

Transforming an existing product into the on-the-go format Reshaping the packaging of baby shampoos Launching a well-established product in a new market Reaching the market with a new product as soon as possible Understanding how to develop something completely new Framing the problem surrounding an abstract idea

\section{Table 2 Data collection}

\begin{tabular}{|c|c|c|c|}
\hline Source & Type of data & Evidence & Use in the analysis \\
\hline \multirow[t]{4}{*}{ Primary } & $\begin{array}{l}\text { First Round: Semi- } \\
\text { structured Interviews }\end{array}$ & $\begin{array}{l}2 \text { interviews } \\
100 \text { minutes } \\
8 \text { pages of transcript }\end{array}$ & $\begin{array}{l}\text { Gathering data regarding the four dimensions of the } \\
\text { protocol, participation, process, purpose and prototype }\end{array}$ \\
\hline & Second Round: & 4 interviews & \multirow{3}{*}{$\begin{array}{l}\text { Expanding and enhancing the validity of the insights } \\
\text { gathered in the first set of interviews. }\end{array}$} \\
\hline & Semi-structured & 530 minutes & \\
\hline & Interviews & 34 pages of transcript & \\
\hline \multirow[t]{4}{*}{ Secondary } & Offline & Annual report (136 pages) & \multirow{2}{*}{$\begin{array}{l}\text { Triangulating information from interviews with facts and } \\
\text { evidence emerging from archival data of the } 6 \text { projects }\end{array}$} \\
\hline & & $\begin{array}{l}\text { Sprint Playbook ( } 31 \text { ) } \\
\text { Sprint documentation (145 slides) }\end{array}$ & \\
\hline & Online & Website and more than 10 academic & Supporting and Integrating and crosschecking general \\
\hline & & and practitioner-oriented articles & $\begin{array}{l}\text { information about the approach gathered during } \\
\text { interviews }\end{array}$ \\
\hline
\end{tabular}


lens an interpretative understanding of the evidence was proposed. Fourth, the interpretation was discussed with the informants and finally, fifth, refined by the authors.

The unit of analysis of this study is the single Design Sprint project, and especially the cough and cold product group in the J\&J consumer health R\&D unit. For each project, we searched for insights on the timing, team and tool dimensions characterizing the development of the projects. After this initial within-case analysis, we moved to a cross-case analysis of the six projects. Comparing the different projects allowed us to gain insights on their commonalities and differences. Unfortunately, for confidentiality reason we cannot disclose the different projects, but we can say that we searched for heterogeneity in each project's nature and homogeneity in the approach adopted to unfold the microfoundations of the J\&J approach to Design Sprint in highly regulated markets.

\section{Findings}

\section{The traditional approach towards innovation in J\&J}

J\&J has operated in the medical device, consumer health and pharmaceutical industry since 1886, serving several markets with many different products. In particular, the company is defined as a Family of Companies, with more than 50 brands under the J\&J umbrella, among which the most famous in the consumer health sector are Band-Aid, Tylenol, Johnson's Baby, Neutrogena, Carefree and Piz Buin. Given the inherent complexity of the brand and product range, no single approach to innovation and managing uncertainty is feasible. Moreover, within the J\&J Family of Companies, Consumer Health $R \& D$ is divided into three main areas - self-care, skin health and essential care. R\&D is dedicated to two main activities, research and discovery of new technologies or providing solutions in collaboration with other functions, such as marketing, strongly based on Voice of the Customer ( $\mathrm{VoC}$ ) insights. Traditionally, the company targeted market-pull projects, in other words, responding to a market need:

The J\&J Consumer Health sector has a long history of innovations that originated from our internal labs. We have seen over the last few years a strong shift on the source of innovations from internally driven to externally adopted. The tiger share of new products introduced to the market has come from outside. The ability to partner externally has become a strategic capability. (J\&J R\&D Manager)

Despite the tension toward market-pull projects, it became evident that this approach led to significant innovation delays. Indeed, collecting data and insights from the market requires time, time that is added to the development and approval of the technology, which requires almost three to five years. Thus, adding the years of market research to R\&D activities implies a time span of over six or seven years to market a new product. This is reasonable if the technology is a new molecule or chemical component, but not if the innovation concerns packaging, for example. Moreover, the long approval and development times do not allow interacting with end users, customers and potential collaborators before a long-time span. This absence from the market is due to the strict regulations. Thus, tight regulations paired with a traditional approach to innovation, with stage gates, might hinder the possibility to reduce the time and innovate solutions that are more valuable for end users.

\section{The emerging J\&J R\&D approach towards innovation: Design Sprint}

In 2017, to cope with the issue of distance from the market and long-time span between ideation and implementation, J\&J R\&D started to pilot a new approach, drawing inspiration from the Design Sprint methodology that Google Ventures proposed in 2016, and hybridizing different agile methodologies. This new approach is focused on the start of the process to reduce to the minimum the time needed to identify new opportunities, whether coming from the market or internally, and therefore the time to submit new products for 
regulatory agencies approval. The main aim was to cope with the limitation, pertaining the pharmaceutical highly regulated market, of the involvement of users in front end innovation. To this end, the R\&D managers carried out six different projects over the period 2017-2019 aimed at exploring working methodologies and identifying the teams and tools needed to cope with this limitation, while complying with the regulations imposed. The first requirement identified was changing the mindset:

We needed to continuously grow the capabilities needed for a flexible and scalable R\&D organization that is able to innovate and to manage more projects through leveraging external resources and strategic partners. (J\&J R\&D Manager)

The introduction of these new capabilities would lead to a more flexible organization, able to cope with uncertain decision-making and the involvement of external partners in the very early stages of the projects. A different mindset can help companies in considering regulations as an opportunity rather than as a limitation for innovation. In J\&J managers, albeit the limitation of the regulation, explored and decided to cooperate with strategic partners even before validating a budget for a new product to anticipate any possible production restrictions. This happened for example in transforming packaging (S1), whereby interacting with external partners and potential future collaborators J\&J was able in a sprint of a couple of days to assess that the new format required a different path for approval from the one imagined previously. This shows how Design Sprint methodology and co-creation workshops allow to anticipate restrictions and to involve experts since the very beginning of the project. Notwithstanding this, the involvement of external experts might unleash the NIH (Not Invented Here) syndrome. Indeed, for a high tech and closed organization, as in the case of $\mathrm{J} \& \mathrm{~J}$, opening the discussion to partners in the early stages is not easy, and requires a framework, methodology, and a set of practices that J\&J introduced with the Sprint Playbook (Figure 1). In particular, this book illustrates the methodology rooted in experimentation and different screening analyses, deployed at the beginning to reduce the risk of failure and anticipate any development constraints.

From our in-depth analysis of the six projects, the analysis of the playbook and the unfolding of the link between approaches and the highly regulated market characteristics, we were able to detect a new approach. For example, two out of the six projects reported in Table 1 were entirely managed by internal J\&J members, in accordance with J\&J's traditional approach to prevent the spillover of knowledge, thus relying only on internal resources at

\section{Figure 1 Snapshot of the J\&J Sprint PlayBook}

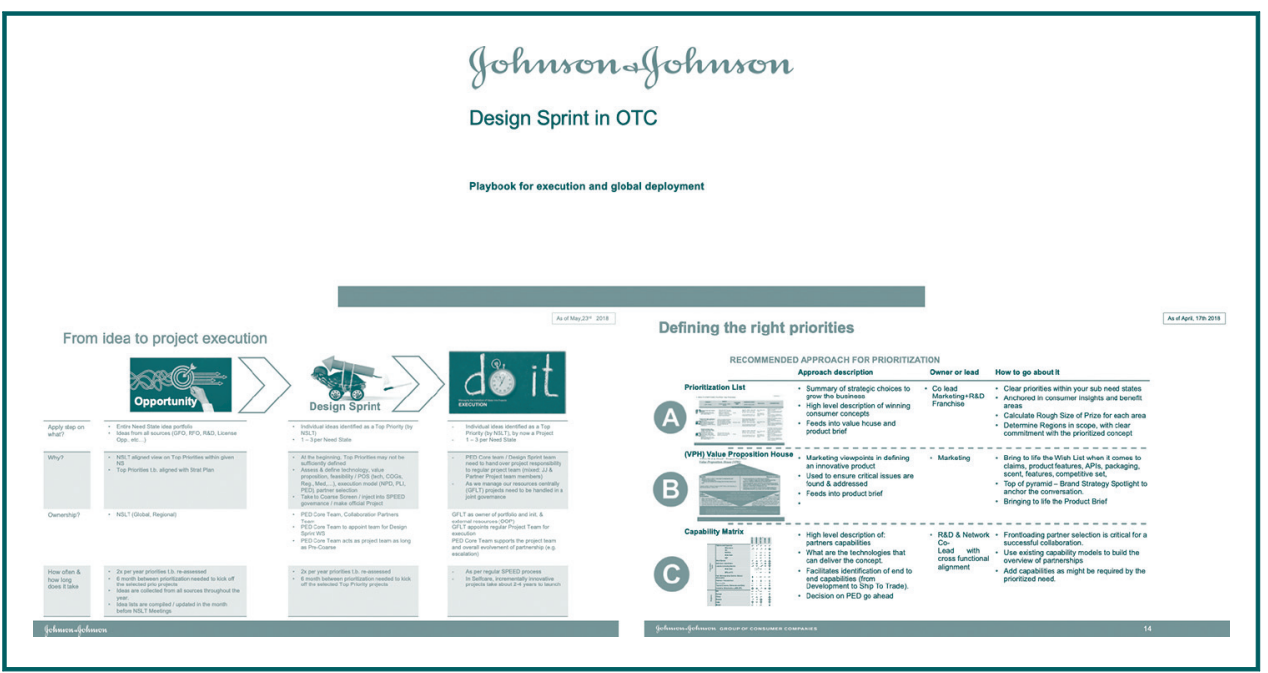


the beginning of the process. However, the informants reported greater success when external parties were involved. Indeed, involving different actors in the supply chain in the other four projects enabled to anticipate the risks:

Can we accelerate ideas by working on those ideas with an external partner? That's a different hypothesis compared to the traditional idea, which is: this is what I want and I will try to find someone who could make it. [.. .] What we wanted to test was not the project itself, but whether it was something that we could do and in the fastest way possible. In addition, we wanted to learn to do these things in a way to anticipate the risks, and external partners are definitely useful for this. (J\&J Self Care R\&D Director)

Shifting from internal to external projects seems to have boosted more experimental learning within the team. By interacting with external partners, more knowledge was acquired, also helping in dealing with the timing issues and reducing the risk of failure in the approval process. Therefore, the sprint mindset demonstrated to the managers that external partners are useful in speeding up the process, as was the case in the S1 project:

We must radically change the way we operate to keep up with consumer needs. Partnering externally allows R\&D to accelerate time to market and access new technologies sharing risk upfront. (J\&J, Self-Care VP R\&D)

Finally, the analysis of the six projects showed that the tools used were differed but had some common elements. First, having clear guidelines was crucial (Sprint Playbook), and the activities that usually lasted a maximum of one or two days, including on-boarding, envisioning, discussing and debriefing, were essential for the success of the sprint. Second, using tools, paper and post-it notes to rapidly prototype the solutions and the intuitions was crucial in many of the sprints. Being able to visualize the solution allowed the teams to express their concerns and speed up the process, as in the case of S2 reported below:

A sprint that was a huge success occurred with bringing in experts with manufacturing capabilities, experts of bottles, experts of caps, experts of pumps, and we brought all of them together. So, four companies worked in co-design and on making decisions on the design features during the sprint by looking at renderings and mock-ups created live in the session, this had a big impact on the performance of the product. (J\&J Self Care R\&D Director)

The analysis of the J\&J case and the six sprint projects has allowed us to shed light on how companies operating in highly regulated markets might adopt design methodologies that require user-centered approaches, as well as prototyping and involvement of different players in the innovation projects. While a customer focus is crucial for market success (Von Hippel, 2010), less is known about the difficulties of adopting a customer-centric approach in highly regulated markets. Our findings show that by adopting Design Sprint, J\&J was able to improve its innovation capabilities notwithstanding the regulatory constraints (Alt and Puschmann, 2005). As a matter of fact, the six projects leveraged different solutions to visualize products and technologies from paper sketches, to virtual 3D rendering to video simulations to share with stakeholders the potential future solutions. These clearly embrace the mantra of Design Sprint, learning from the surface (Knapp et al., 2016), leveraging even early prototypes, the so-called pretotype (Magistretti et al., 2020b). Thus, the above findings show that, within Design Sprint, there are three main characteristics: the team composition, the time of the experimentation and the tools adopted that are crucial in a highly regulated market. Therefore, we can summarize the microfoundation of Design Sprint in highly regulated markets in a $3 T$ model (team, timing, tools) emerging from the J\&J expertise, here proposed in Figure 2. 


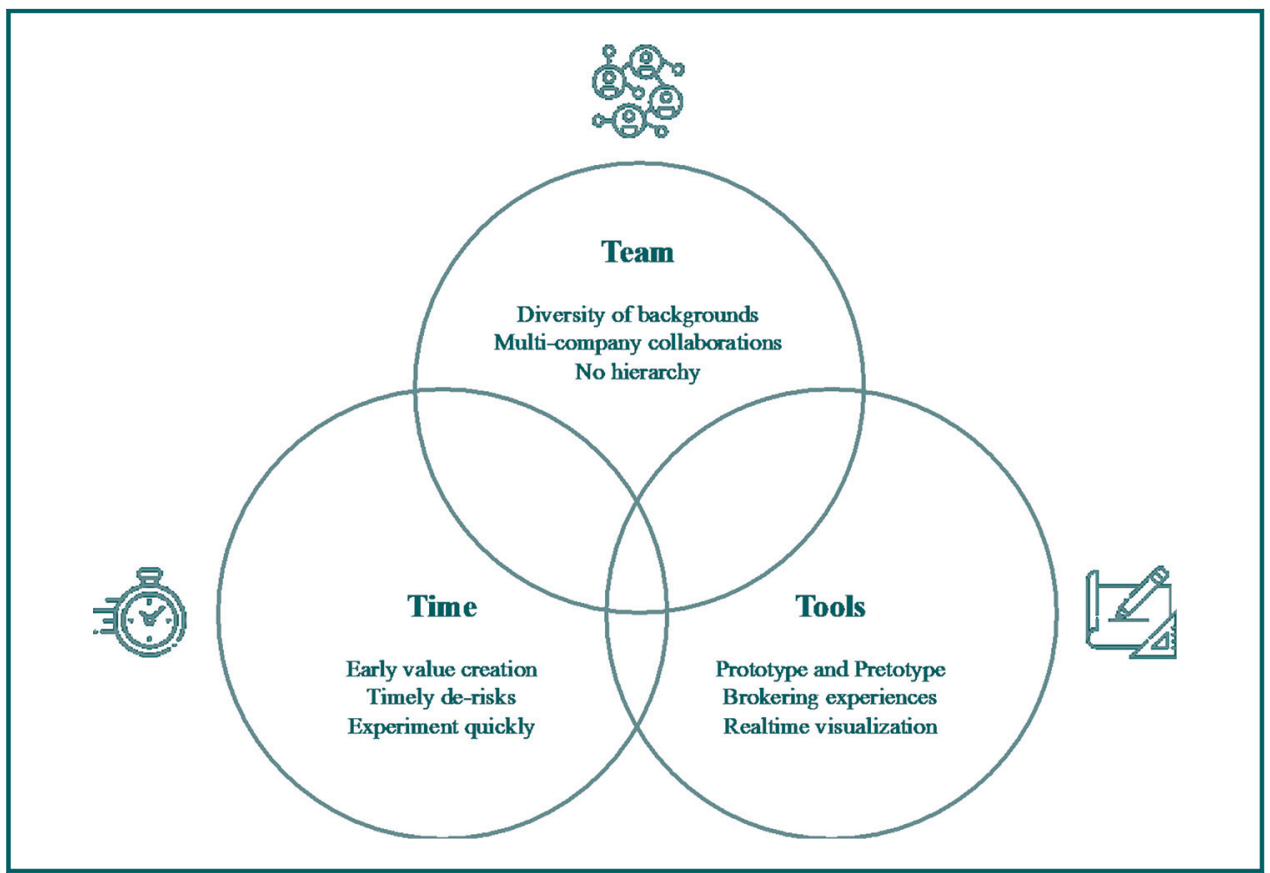

\section{Discussion}

This case study contributes to three main streams of literature. First, to Design Sprint literature (Knapp et al., 2016) by unfolding the microfoundations of this process. Second, to the management of innovation in highly regulated markets (Schiavone and Simoni, 2019) by unveiling the role of design in turbulent and uncertainty market. Third, to the literature on knowledge management (Simeone et al., 2017) by highlighting the role of early prototyping as a means of knowledge transfer in a highly regulated market. Our qualitative research also contributes to the ongoing debate on approaches and methodologies that might foster innovation in turbulent and uncertain environments (Sawhney and Prandelli, 2000; Bicen and Johnson, 2015).

\section{The microfoundations of Design Sprint in highly regulated markets}

Moving to the first contribution, by comparing the six projects and the different insights gathered from the primary and secondary sources, the analysis unfolds the microfoundations of Design Sprint. Our study shows the relevance of the individual, process and structure dimensions, ultimately the microfoundations of innovation (Felin et al., 2012), to favor more user-centered innovation in highly regulated markets by clarifying how J\&J, by adopting Design Sprint, was able to interact differently with end users while complying with the regulations.

Concerning the team and individuals, first microfoundation (Barney and Felin, 2013), our study unfolds the microfoundational dimension of Design Sprint in highly regulated markets. Indeed, it is not only the capabilities and mindsets of those involved in the process that facilitate innovation (Liedtka, 2018) but also their ability to involve people from outside (Chesbrough, 2006). The individual dimension of innovation is not only related to the technical but also the behavioral dimension, enabled by an open mindset and skills other than purely technical, as in the case of projects S4 and S6 analyzed. Indeed, for a company operating in the pharmaceutical industry, recognized as a highly regulated market, the 
ability to discuss innovations in a collaborative way, with external partners in a multicompany dimensions, is counterintuitive. Especially as in pharmaceutical R\&D, openness and collaboration tend not to be well accepted due to spillover risks (Pisano and Verganti, 2008; Magistretti et al., 2020b). Our case study instead shows that collaborating in the early stages enables anticipating the risks of future failures. Thus, the study also contributes to the open innovation literature (Chesbrough and Appleyard, 2007), demonstrating that an open innovation and especially inbound strategy can radically support innovation in highly regulated markets by allowing a fruitful debate with end users.

The second contribution is on the process microfoundation (Felin et al., 2012) especially on the timing dimension of the innovation process. The case taught us that to boost innovation in highly regulated markets companies must timely anticipate the risk assessment, and there is no better way to do that than involving external partners and embracing an experimentation approach (Magistretti et al., $200 \mathrm{~b}$ ). This is in line with the surge of the design thinking (Carlgren et al., 2016; Micheli et al., 2019) and agile methodologies (Cooper, 2016) where experimentation and iteration during concept creation and framing help in anticipating constraints. Albeit new, it is useful in highly regulated markets where rules regulate the experimentation and user testing of early Minimum Viable Products owing to the approval required for the products to be developed. Moreover, the projects analyzed illustrate the crucial significance of the prototyping phase in highly regulated markets (Kaplan et al., 2004), as well as different forms of value creation that allow identifying potential future problems or exploring new opportunities. Hence, highly regulated markets that are usually characterized by process efficient innovation (Blind, 2016) can experience also product innovation, if time is properly managed, as our evidence on J\&J shows. Thus, we contribute to experimentation literature (Thomke, 2020) by showing how quick and early experimentation can timely reduce risks of future failure by sharing knowledge and assess ideas in the early stages of the value creation process.

The third contribution is at the structure level of microfoundation and especially concerning the tools. The team involved in the project is more effective if the members come from both within and outside the company. This type of open collaboration supports creativity and enables the management to counter myopia (Unsworth, 2001). The J\&J case study shows that adopting early prototyping and new tools, such as the Sprint PlayBook to guide and manage the adoption and implementation of Design Sprint, leads to a more entrepreneurial behavior, to creativity, and overcoming any innovation constraints (Ghezzi et al., 2020). Indeed, increasing managerial creativity and finding ways to experiment are crucial for small firms and startups, and also increasingly relevant for multinationals (Ko and Butler, 2007; Kohler, 2016; Oliva and Kotabe, 2019). Adopting the prototyping and real time visualization allows companies to adapt their structure toward interoperable business units. The J\&J case and the Design Sprint projects show that alongside workshops a microfoundational view of design is needed (Olson et al., 2005). In doing so, the team that facilitates the sprint is a sort of broker for the whole company, searching for people with the abilities and skills to contribute to the project according to the scope of the specific tools and tasks required. This aspect is counterintuitive in highly regulated markets where institutional and social rules usually hinder the communication and cooperation of stakeholders (Blind et al., 2017). Thus, this paper contributes to the theory by unfolding the need of a more open collaboration and real-time co-creation to share knowledge and spark innovation. Table 3 summarizes the microfoundations of Design Sprint in highly regulated markets versus non-regulated ones, reconciling what we know from theory and practice.

\section{Innovation and knowledge in highly regulated markets}

The article also contributes to the role that design might play in overcoming limitations in innovation endeavors imposed by tight regulations (Blind, 2016). The J\&J case highlighted how being able to engage different potential partners with design workshops can be 
Table 3 Microfoundations of design sprint in highly regulated markets

\begin{tabular}{|c|c|c|}
\hline Microfoundations & $\begin{array}{l}\text { In non-regulated markets } \\
\text { Knapp et al. (2016); Dell' Era et al. (2020); Magistretti et al. } \\
\text { (2020b) }\end{array}$ & $\begin{array}{l}\text { In highty regulated markets } \\
\text { (Emerging from the J\&J case) }\end{array}$ \\
\hline \multicolumn{3}{|l|}{ Felin et al. (2012) } \\
\hline \multirow[t]{5}{*}{ Individual } & Team & Team \\
\hline & Diversity of backgrounds & Diversity of backgrounds \\
\hline & $\begin{array}{l}\text { Defined number of members with specific roles, on average } \\
7\end{array}$ & $\begin{array}{l}\text { Collaboration among different team members, coming } \\
\text { from different companies }\end{array}$ \\
\hline & Presence of a Decider within the company & Absence of hierarchy between companies \\
\hline & Corporate participants & Corporate and non- corporate participants \\
\hline \multirow[t]{3}{*}{ Process } & Time & Time \\
\hline & $\begin{array}{l}\text { Five-day process (i.e., Map, Sketch, Define Prototype and } \\
\text { Test) }\end{array}$ & $\begin{array}{l}\text { Focus on experimentation of insights and rough ideas } \\
\text { De-risk as soon as possible }\end{array}$ \\
\hline & Fast product crafting and launch to get feedback & Early understanding of value creation \\
\hline \multirow[t]{4}{*}{ Structure } & Tools & Tools \\
\hline & Ability to interact with experts & Prototype and pretotype ideas \\
\hline & Leverage prototypes to validate hypotheses & $\begin{array}{l}\text { Brokering experience during debates within and } \\
\text { across organizational boundaries }\end{array}$ \\
\hline & & Real-time visualization \\
\hline
\end{tabular}

pursued also in highly regulated markets. It stresses that if Design Sprint workshops are managed properly, they can support open innovation (Chesbrough, 2006; Pellizzoni et al., 2019) in highly regulated markets to avoid the problems related to spillovers or NHI for a better cooperation in anticipating potential future restrictions. Design Sprint focused on prototyping to visualize core aspects of this methodology (Carlgren et al., 2016), to show how, even in highly regulated markets, design mindsets comprising co-creation and prototyping can foster innovation due to early assessment of ideas and insights.

The last contribution of the research is towards knowledge management in highly regulated markets by adopting Design Sprint. Our findings indicate that different prototyping tools, such as sketching, rendering and visualization, might significantly increase the ability to anticipate the risks and knowledge transferring (Simeone et al., 2017). Indeed, by early prototyping and sketching knowledge is transferred in a more structured way and this supports the alignment and the sharing of information from the early stages of innovation (Latilla et al., 2019). We contribute to the innovation literature (Homa, 1995; D'Adderio, 2001; Cadden and Downes, 2013) by showing that early prototypes in highly regulated markets are possible, if the mindset shifts from the long to the short term. Indeed, researchers in R\&D centers in this case cannot prototype in the early stages nor can they ask consumers to test new drugs, but they need to craft new solutions more creatively in to test the assumptions in the early stage by interacting with stakeholders without contravening the regulations (Faccin et al., 2019). J\&J has been able to do this by leveraging early paper prototyping, real-time rendering and simulations, allowing to create the technologies and validate the concept before submitting them for approval.

\section{Conclusions}

This paper unfolds three main aspects: first it unveils the microfoundations of Design Sprint by showing the $3 \mathrm{~T}$ model adopted by J\&J; second it shows the value of experimentation in highly regulated markets, especially in the ones where user involvement is challenged by regulations; and third, it highlights the value of prototyping as a means of knowledge sharing and transferring. Although not generalizable, the benefits are tangible and might inspire future adopters, especially when the main challenge is about human-centered design and user involvement in a highly regulated market. Indeed, the identification of the 
microfoundations of Design Sprint as team, time and tools extends the relevance of crossfunctional teams, time and know-how related to prototyping tools in the early innovation stages in a highly regulated market. This case study of a leading world-class pharmaceutical company has allowed us to unpack the microfoundations (Felin et al., 2012) of the Design Sprint approach for innovation. Indeed, our findings highlight the importance of cross-functional teams to overcome the user involvement constraints in highly regulated markets, the timing of the process and early prototyping to speed up the innovation process. In brief, this study contributes to the different streams of literature by answering to a number of open calls. In design management, by showing how approaches like Design Sprint that can support innovation in specific contexts (Micheli et al., 2019). In knowledge management, by explaining how Design Sprint and prototype management can boost innovation in complex environments by facilitating transferring of knowledge (Iansiti, 1995; Bednar and Welch, 2006; Latilla et al., 2019). Finally, in experimentation literature by showing how experimentation with end users can be enacted in complex and regulated market thanks to Design Sprint (Thomke, 2020). Practitioners can benefit from our findings by being informed on how innovation can be boosted in the early stages of projects through relevant decisions on the team, time and tool dimensions in a highly regulated market: underestimating one of these dimensions might hamper the overall results of the innovation process.

Although the findings of our study are based on a single and not generalizable case, they contribute to enriching our knowledge on innovation processes rooted in end user involvement and building new business paradigms. We hope they might inspire new contributions related to highly regulated markets and the integration of the team, timing and tool dimensions.

\section{Acknowledgment}

The authors would like to thank the editors and anonymous reviewers, who helped significantly in enhancing the study's contributions. The authors would also thank Filippo Mazzoni for his support in the initial activity of this research.

\section{References}

Alt, R. and Puschmann, T. (2005), "Developing customer process orientation: the case of pharma corp", Business Process Management Journal, Vol. 11 No. 4, pp. 297-315.

Amable, B., Ledezma, I. and Robin, S. (2016), "Product market regulation, innovation, and productivity", Research Policy, Vol. 45 No. 10, pp. 2087-2104.

Artusi, F., Bellini, E., Dell'Era, C. and Verganti, R. (2020), "Designing an Omni-Experience to save retailing: lessons from an Italian book retailer", Research-Technology Management, Vol. 63 No. 3 , pp. 24-32.

Barczak, G., Griffin, A. and Kahn, K.B. (2009), "Perspective: trends and drivers of success in NPD practices: results of the 2003 PDMA best practices study", Journal of Product Innovation Management, Vol. 26 No. 1, pp. 3-23.

Barney, J.A.Y. and Felin, T. (2013), "What are microfoundations?", Academy of Management Perspectives, Vol. 27 No. 2, pp. 138-155.

Bednar, P.M. and Welch, C. (2006), "Structuring uncertainty: Sponsoring innovation and creativity", In F. Adam, P. Brezillon, S. Carlsson, P. Humphreys (Eds), Creativity and Innovation in Decision Making and Decision Support, Decision Support Press, pp. 867-885.

BenMahmoud-Jouini, S. and Midler, C. (2020), "Unpacking the notion of prototype archetypes in the early phase of an innovation process", Creativity and Innovation Management, Vol. 29 No. 1, pp. 49-71.

Bicen, P. and Johnson, W.H. (2015), "Radical innovation with limited resources in high-turbulent markets: the role of lean innovation capability", Creativity and Innovation Management, Vol. 24 No. 2, pp. 278-299. 
Blind, K. (2016), "The impact of regulation on innovation", In Handbook of Innovation Policy Impact, Edward Elgar Publishing.

Blind, K., Petersen, S.S. and Riillo, C.A. (2017), "The impact of standards and regulation on innovation in uncertain markets”, Research Policy, Vol. 46 No. 1, pp. 249-264.

Brand, M., Tiberius, V., Bican, P.M. and Brem, A. (2019), "Agility as an innovation driver: towards an agile front end of innovation framework", Review of Managerial Science, pp. 1-31.

Brown, T. (2008), "Design thinking”, Harvard Business Review, Vol. 86 No. 6, pp. 84-95.

Buchanan, R. (1992), "Wicked problems in design thinking”, Design Issues, Vol. 8 No. 2, pp. 5-21.

Cadden, T. and Downes, S.J. (2013), "Developing a business process for product development", Business Process Management Journal, Vol. 19 No. 4, pp. 715-736.

Carlgren, L., Rauth, I. and Elmquist, M. (2016), "Framing design thinking: the concept in idea and enactment", Creativity and Innovation Management, Vol. 25 No. 1, pp. 38-57.

Cavallo, A., Sanasi, S., Ghezzi, A. and Rangone, A. (2020), "Competitive intelligence and strategy formulation: connecting the dots", Competitiveness Review: An International Business Journal, Vol. 31 No. 2.

Chesbrough, H. (2006), Open Business Models: How to Thrive in the New Innovation Landscape, Harvard Business Press.

Chesbrough, H.W. and Appleyard, M.M. (2007), "Open innovation and strategy", California Management Review, Vol. 50 No. 1, pp. 57-76.

Cooper, R.G. (2016), "Agile-Stage-Gate hybrids: the next stage for product development blending agile and Stage-Gate methods can provide flexibility, speed, and improved communication in new-product development", Research-Technology Management, Vol. 59 No. 1, pp. 21-29.

Cooper, R.G. and Sommer, A.F. (2016), "The agile-stage-gate hybrid model: a promising new approach and a new research opportunity", Journal of Product Innovation Management, Vol. 33 No. 5, pp. 513-526.

D'Adderio, L. (2001), "Crafting the virtual prototype: how firms integrate knowledge and capabilities across organisational boundaries", Research Policy, Vol. 30 No. 9, pp. 1409-1424.

Dell'Era, C., Magistretti, S., Cautela, C., Verganti, R. and Zurlo, F. (2020), "Four kinds of design thinking: from ideating to making, engaging, and criticizing", Creativity and Innovation Management, Vol. 29 No. 2, pp. 324-344.

Donmoyer, R. (2000), "Generalizability and the single-case study", in R. Gomm, M. Hammersley, and P. Foster (Eds), Case Study Method: Key Issues, Key Texts, Sage Publications, pp. 45-68.

Dorst, K. (2011), "The core of 'design thinking' and its application”, Design Studies, Vol. 32 No. 6, pp. 521-532.

Faccin, K., Balestrin, A., Martins, B.V. and Bitencourt, C.C. (2019), "Knowledge-based dynamic capabilities: a joint R\&D project in the French semiconductor industry", Journal of Knowledge Management, Vol. 23 No. 3.

Felin, T., Foss, N.J., Heimeriks, K.H. and Madsen, T.L. (2012), "Microfoundations of routines and capabilities: individuals, processes, and structure", Journal of Management Studies, Vol. 49 No. 8, pp. 1351-1374.

Foxon, T. and Pearson, P. (2008), "Overcoming barriers to innovation and diffusion of cleaner technologies: some features of a sustainable innovation policy regime", Journal of Cleaner Production, Vol. 16 No. 1, pp. S148-S161.

Ghezzi, A., Cavallo, A., Sanasi, S. and Rangone, A. (2020), "Opening up to startup collaborations: open business models and value co-creation in SMEs", Competitiveness Review: An International Business Journal.

Gibson, C.B. and Birkinshaw, J. (2004), "The antecedents, consequences, and mediating role of organizational ambidexterity”, Academy of Management Journal, Vol. 47 No. 2, pp. 209-226.

Giudici, A., Reinmoeller, P. and Ravasi, D. (2018), "Open-system orchestration as a relational source of sensing capabilities: evidence from a venture association", Academy of Management Journal, Vol. 61 No. 4, pp. 1369-1402.

Homa, P. (1995), "Business process re-engineering: theory- and evidence-based practice", Business Process Management Journal, Vol. 1 No. 3, pp. 10-30. 
Huberman, M. and Miles, M.B. (2002), The Qualitative Researcher's Companion, Sage.

Iansiti, M. (1995), "Technology integration: managing technological evolution in a complex environment", Research Policy, Vol. 24 No. 4, pp. 521-542.

Jin-Hai, L., Anderson, A.R. and Harrison, R.T. (2003), "The evolution of agile manufacturing", Business Process Management Journal, Vol. 9 No. 2, pp. 170-189.

Kaplan, A.V., Baim, D.S., Smith, J.J., Feigal, D.A., Simons, M., Jefferys, D., ... Leon, M.B. (2004), "Medical device development: from prototype to regulatory approval", Circulation, Vol. 109 No. 25, pp. 3068-3072.

Knapp, J., Zeratsky, J. and Kowitz, B. (2016), Sprint: How to Solve Big Problems and Test New Ideas in Just Five Days, Simon and Schuster.

Ko, S. and Butler, J.E. (2007), "Creativity: a key link to entrepreneurial behavior", Business Horizons, Vol. 50 No. 5, pp. 365-372.

Kohler, T. (2016), "Corporate accelerators: building bridges between corporations and startups", Business Horizons, Vol. 59 No. 3, pp. 347-357.

Kreiser, P.M., Kuratko, D.F., Covin, J.G., Ireland, R.D. and Hornsby, J.S. (2019), "Corporate entrepreneurship strategy: extending our knowledge boundaries through configuration theory", Small Business Economics, pp. 1-20.

Kyakulumbye, S., Pather, S. and Jantjies, M. (2019), "Knowledge creation in a participatory design context: the use of empathetic participatory design", Electronic Journal of Knowledge Management, Vol. 17 No. 1.

Latilla, V.M., Frattini, F., Petruzzelli, A.M. and Berner, M. (2019), "Knowledge management and knowledge transfer in arts and crafts organizations: evidence from an exploratory multiple case-study analysis", Journal of Knowledge Management.

Liedtka, J. (2018), "Why design thinking works”, Harvard Business Review, Vol. 96 No. 5, pp. 72-79.

Luukkonen, T. (1998), "The difficulties in assessing the impact of EU framework programmes", Research Policy, Vol. 27 No. 6, pp. 599-610.

McKelvey, M., Alm, H. and Riccaboni, M. (2003), "Does co-location matter for formal knowledge collaboration in the Swedish biotechnology-pharmaceutical sector?", Research Policy, Vol. 32 No. 3, pp. 483-501.

Madrid-Guijarro, A., Garcia, D. and Van Auken, H. (2009), "Barriers to innovation among Spanish manufacturing SMEs", Journal of Small Business Management, Vol. 47 No. 4, pp. 465-488.

Magistretti, S., Dell'Era, C. and Doppio, N. (2020b), "Design sprint for SMEs: an organizational taxonomy based on configuration theory", Management Decision, Vol. 58 No. 9.

Magistretti, S., Dell'Era, C., Frattini, F. and Petruzzelli, A.M. (2020a), "Innovation through tradition in design-intensive family firms", Journal of Knowledge Management, Vol. 24 No. 4.

Malsch, F. and Guieu, G. (2019), "How to get more with less? Scarce resources and high social ambition: effectuation as KM tool in social entrepreneurial projects", Journal of Knowledge Management, Vol. 23 No. 10.

Mansoori, Y. and Lackeus, M. (2019), "Comparing effectuation to discovery-driven planning, prescriptive entrepreneurship, business planning, lean startup, and design thinking”, Small Business Economics, pp. 1-28.

Marino, M., Parrotta, P. and Valletta, G. (2019), "Electricity (de) regulation and innovation", Research Policy, Vol. 48 No. 3, pp. 748-758.

Micheli, P., Wilner, S.J., Bhatti, S.H., Mura, M. and Beverland, M.B. (2019), "Doing design thinking: conceptual review, synthesis, and research agenda", Journal of Product Innovation Management, Vol. 36 No. 2, pp. 124-148.

Oliva, F.L. and Kotabe, M. (2019), "Barriers, practices, methods and knowledge management tools in startups", Journal of Knowledge Management, Vol. 23 No. 9.

Olson, E.M., Slater, S.F. and Hult, G.T.M. (2005), "The importance of structure and process to strategy implementation", Business Horizons, Vol. 48 No. 1, pp. 47-54.

Pellizzoni, E., Trabucchi, D. and Buganza, T. (2019), "When agility meets open innovation: two approaches to manage inbound projects", Creativity and Innovation Management, Vol. 28 No. 4, pp. 464-476. 
Pellizzoni, E., Trabucchi, D., Frattini, F., Buganza, T. and Di Benedetto, A. (2020), "Leveraging stakeholders' knowledge in new service development: a dynamic approach", Journal of Knowledge Management, Vol. 24 No. 2.

Pisano, G.P. and Verganti, R. (2008), "Which kind of collaboration is right for you", Harvard Business Review, Vol. 86 No. 12, pp. 78-86.

Quan, X., Xiao, H., Ji, Q. and Zhang, J. (2020), "Can innovative knowledge management platforms lead to corporate innovation? Evidence from academician workstations in China", Journal of Knowledge Management, Vol. 25 No. 1.

Ries, E. (2011), The Lean Startup: How Today's Entrepreneurs Use Continuous Innovation to Create Radically Successful Businesses, Currency.

Savino, T., Petruzzelli, A.M. and Albino, V. (2017), "Teams and lead creators in cultural and creative industries: evidence from the Italian haute cuisine", Journal of Knowledge Management, Vol. 21 No. 3.

Sawhney, M. and Prandelli, E. (2000), "Communities of creation: managing distributed innovation in turbulent markets", California Management Review, Vol. 42 No. 4, pp. 24-54.

Schiavone, F. and Simoni, M. (2019), "Strategic marketing approaches for the diffusion of innovation in highly regulated industrial markets: the value of market access", Journal of Business \& Industrial Marketing, Vol. 34 No. 7, pp. 1606-1618, doi: 10.1108/JBIM-08-2018-0232.

Schubert, T. and Tavassoli, S. (2020), "Product innovation and educational diversity in top and Middle management teams", Academy of Management Journal, Vol. 63 No. 1, pp. 272-294.

Seawright, J. and Gerring, J. (2008), "Case selection techniques in case study research: a menu of qualitative and quantitative options", Political Research Quarterly, Vol. 61 No. 2, pp.294-308.

Siggelkow, N. (2007), "Persuasion with case studies", Academy of Management Journal, Vol. 50 No. 1, pp. 20-24.

Simeone, L., Secundo, G. and Schiuma, G. (2017), "Knowledge translation mechanisms in open innovation: the role of design in R\&D projects", Journal of Knowledge Management, Vol. 21 No. 6.

Thomke, S. (2020), "Building a culture of experimentation", Harvard Business Review, Vol. 98 No. 2, pp. 40-47.

Trabucchi, D., Sanasi, S., Ghezzi, A. and Buganza, T. (2020), "Idle asset hunters - the secret of multisided platforms”, Research-Technology Management, Vol. 64 No. 1, pp. 33-42.

Unsworth, K. (2001), "Unpacking creativity”, Academy of Management Review, Vol. 26 No. 2, pp. 289-297.

Verganti, R. (2009), Design Driven Innovation: Changing the Rules of Competition by Radically Innovating What Things Mean, Harvard Business Press.

Von Hippel, E. (2010), "Open user innovation", In B.H. Hall and N. Rosenberg (Eds), Handbook of the Economics of Innovation, North-Holland, pp. 411-427.

Von Zedtwitz, M. and Gassmann, O. (2002), "Market versus technology drive in R\&D internationalization: four different patterns of managing research and development", Research Policy, Vol. 31 No. 4, pp. 569-588.

Wang, G., Dou, W., Zhu, W. and Zhou, N. (2015), "The effects of firm capabilities on external collaboration and performance: the moderating role of market turbulence", Journal of Business Research, Vol. 68 No. 9, pp. 1928-1936

Wilson, K. and Doz, Y.L. (2011), "Agile innovation: a footprint balancing distance and immersion", California Management Review, Vol. 53 No. 2, pp. 6-26.

Wu, W.L. and Lee, Y.C. (2017), "Empowering group leaders encourages knowledge sharing: integrating the social exchange theory and positive organizational behavior perspective", Journal of Knowledge Management, Vol. 21 No. 2.

Yin, R.K. (2011), Applications of Case Study Research, Sage. 


\section{Appendix}

Dimension: participation:

- Who are the stakeholders involved during the prototyping process?

- When do you involve the stakeholders during your innovation process?

- Are the people involved during the prototyping process internal or external to the company?

- What are you looking for when interacting with other stakeholders?

Dimension: process:

- Why are you willing to anticipate the prototyping process?

- What added value does an early prototyping process bring to the company?

- How long does the prototyping process take?

- Is it necessary to reduce or increase the time dedicated to prototyping?

Dimension: purpose:

- Why did you decide to develop comprehensive/focused prototypes?

- How do you select the features to be prototyped?

- Do you add features to the prototype during subsequent prototyping cycles?

- How many prototypes do you usually develop?

Dimension: prototyping:

- Do you develop virtual prototypes?

- If yes, how does the adoption of virtual prototyping influence the three dimensions?

- Can you tell me about a real case based on the type of prototyping you told me about?

\section{Corresponding author}

Stefano Magistretti can be contacted at: stefano.magistretti@polimi.it

For instructions on how to order reprints of this article, please visit our website: www.emeraldgrouppublishing.com/licensing/reprints.htm

Or contact us for further details: permissions@emeraldinsight.com 